\title{
7 INFANTES 7. LA LEYENDA A LA LUZ DEL SIMBOLISMO TRADICIONAL
}

\section{Enrique Jerez}

ENS Editions | «Cahiers d'études hispaniques médiévales »

2013/1 n $36 \mid$ pages 239 à 255

ISSN 1779-4684

ISBN 9782847885415

DOI 10.3917/cehm.036.0239

Article disponible en ligne à l'adresse :

https://www.cairn.info/revue-cahiers-d-etudes-hispaniquesmedievales-2013-1-page-239.htm

Distribution électronique Cairn.info pour ENS Editions.

(C) ENS Editions. Tous droits réservés pour tous pays.

La reproduction ou représentation de cet article, notamment par photocopie, n'est autorisée que dans les limites des conditions générales d'utilisation du site ou, le cas échéant, des conditions générales de la licence souscrite par votre établissement. Toute autre reproduction ou représentation, en tout ou partie, sous quelque forme et de quelque manière que ce soit, est interdite sauf accord préalable et écrit de l'éditeur, en dehors des cas prévus par la législation en vigueur en France. Il est précisé que son stockage dans une base de données est également interdit. 


\title{
7 infantes 7 \\ La leyenda a la luz del simbolismo tradicional
}

\author{
Enrique JEREZ \\ Proyecto «Formas de la Épica Hispánica: \\ Tradiciones y Contextos Históricos II»
}

Un error muy común es suponer que la forma sverdadera» u «original» de una historia dada puede reconstruirse por una eliminación de sus elementos milagrosos y supuestamente «f antásticos» 0 " "poéticos». Sin embargo, es precisamente en estas «maravillas» [...] donde están inherentes las verdades más profundas de la leyenda.

Ananda K. Coomaraswamy

\section{RESUMEN}

El presente texto explora las posibilidades de exégesis simbólica que subyacen en el motivo del septenario tal como lo transmite la Leyenda de los infantes de Lara. Con este propósito, se analiza (desde una perspectiva comparada) el esquema mítico de la «séptuple progenitura fundadora», a cuya descendencia sugerimos asimilar la hebdómada de Lara. Finalmente, el trabajo propone una interpretación para este recurrente submotivo del folclore narrativo universal, cuya naturaleza y sentido cosmológicos (y aun metafísicos) se intentan desentrañar, y ello conforme a los postulados de la que, en el contexto de los «estudios espirituales», se conoce como Escuela Tradicional o Perennialista.

Palabras clave: Leyenda de los infantes de Lara, septenario, simbolismo narrativo, Escuela Tradicional

RÉSUMÉ

Ce texte explore les possibilités d'exégèse symbolique qui s'occultent dans le motif du 
septénaire comme le transmet la légende des Infantes de Lara. À cet effet, nous analyserons (depuis une perspective comparée) le schéma mythique de la «septuple progéniture fondatrices, auquel nous suggérons d'assimiler l'hebdomade de Lara. Finalement, ce travail propose une interprétation de ce sous-motif récurrent du folklore narratif universel, d'où nous essaierons d'en définir la nature et le sens cosmologiques (et même métaphysique), et cela conformément aux postulats de l'école connue, dans le cadre des "études spirituelles", comme École Traditionnelle ou Pérennialiste.

Mots clés: Légende des infants de Lara, septénaire, symbolisme narratif, École Traditionnelle

Desde sus primeros comentaristas ${ }^{1}$ (y muy notablemente gracias a la labor inaugural de Ramón Menéndez Pidal), la Leyenda de los infantes de Lara ha sido objeto de acercamientos más bien procedentes de la Filología, la Historia literaria o la Historia propiamente dicha, y en cualquier caso a menudo ligados a la cuestión del grado de «veracidad» o «historicidad» que conservan los sucesos narrados en ella. Lo cierto es que, dada la naturaleza de su contenido, nuestra leyenda se presta especialmente a este tipo de análisis, y de hecho resulta un campo sobremanera abonado para el estudio de asuntos tan interesantes como la imbricación entre el discurso histórico y el legendario (lo que se hace explícito desde el propio título del congreso del que da cuenta el presente volumen ${ }^{2}$ ) o el modo en que se va forjando una leyenda histórica. En cualquier caso, aproximaciones

1. El presente trabajo ha conocido una redacción paralela a esta, publicada bajo el título «Folclore y simbolismo narrativo: el motivo del septenario en la literatura tradicional», in: Conciencia: imagen y concepto. Cuadernos del Círculo de Estudios Espirituales Comparados, Sevilla: Alegoría, 2012, p. 87-100, dirigida a un público no especializado en literatura medieval hispánica y sí en tradiciones espirituales; en dicha versión se han suprimido los pasajes específicamente referidos a la leyenda de los infantes de Lara. Como ya indicamos allí, hemos considerado justificable la doble publicación únicamente en virtud de la habitual (y desgraciada) «impermeabilidad» existente entre los dos ámbitos de reflexión concernidos, lo que hace de hecho altamente improbable que cada una de las versiones atraviese, de forma independiente, los férreos límites que sus respectivos radios de influencia les imponen. Por lo demás, queremos expresar nuestra más sincera gratitud al profesor José Manuel Pedrosa, quien nos animó a participar en el congreso de Salas de 2011 y nos facilitó utilísima bibliografía, sin que nada de todo ello le comprometa respecto de las opiniones vertidas en el texto, ni menos de sus posibles defectos o errores. Asimismo, es de ley agradecer a los profesores François Delpech, Alberto Montaner y Mercedes Vaquero sus valiosos comentarios y aportaciones en el transcurso del referido congreso, utilizados con provecho en el presente trabajo.

2. No caben más que felicitaciones a los promotores y organizadores del I Congreso internacional "Los siete infantes de Lara, la historia frente a la leyenda», por la concepción y ejecución de un proyecto que viene a hacer justicia a los extraordinarios valores que, desde distintos puntos de vista, posee esta leyenda. Con todo, una obligada reflexión se impone respecto de un subtítulo (la historia frente a la leyenda) que, a nuestro juicio, incide con excesivo énfasis en la supuesta irreductibilidad (incluso en la abierta oposición) existente entre ambos conceptos, o más bien entre las realidades que designan. Como se tratará de sugerir en estas páginas, la frontera que separa ambos fenómenos es mucho más permeable de lo que el epígrafe en cuestión quiere dar a entender. 
de esta clase nos remiten sin remedio al espinoso problema de clarificar qué es una leyenda histórica (y en última instancia, una leyenda), cuáles son su origen, su sentido, sus motivaciones, su razón de ser.

Una respuesta satisfactoria a semejantes preguntas no puede prescindir de un hecho ampliamente documentado y no por ello menos sorprendente: por encima de etiquetas eruditas («mito», «poema épico», «leyenda», «cuento», «relato hagiográfico», «genealógico», «fundacional», etc.), las narraciones tradicionales tienden a repetir temas, estructuras y motivos semejantes allá donde se las encuentra, salvando a menudo enormes distancias de espacio (en términos geográficos y culturales) y enormes intervalos de tiempo.

Siendo así, para intentar comprender la Leyenda de los infantes de Lara también es obligado adoptar una perspectiva de esta amplitud y, desde la mitología y el folclore comparados, tratar de buscar paralelos válidos que, en el mejor de los casos, puedan remitir a un modelo mítico o legendario más general (si no universal), sobre el que realizar ensayos de interpretación que devuelvan al texto en cuestión al menos algo de su sentido originario $^{3}$. Nuestra aportación (quede dicho ya) quiere adoptar una perspectiva de este tipo, con ambiciones (modestamente) comparativas en el medio y (humildemente) interpretativas en el fin, con la confianza de que, como escribió el hispanista francés Georges Cirot, si bien un poco de crítica nos hace adivinar la leyenda en la historia, un poco más de crítica nos haga descubrir la historia en la leyenda ${ }^{4}$.

\section{La séptuple progenitura: anatomía de un esquema mítico}

La tarea descrita aplicada a toda la Leyenda de los infantes de Lara no hace falta decir que sobrepasa los límites de estas breves líneas, de modo que hemos entresacado de ella un elemento que consideramos de indudable raigambre simbólica, y que está en el centro de la leyenda tal como la conocemos, con la expectativa de poder aportar otros relatos míticos o legendarios paralelos y sugerir una vía de interpretación posible para este tipo de

3. Lo cual, por lo demás, ya hacen brillantemente los profesores François Delpech - en su aportación a este volumen - y José Manuel Pedrosa. Por otra parte, aceptar la existencia de un modelo previo que atrae hacia sí personajes y circunstancias «reales» - o en todo caso «verosímiles» - es una cuestión que nos parece enormemente importante de dilucidar, y que afecta de lleno a la noción de leyenda histórica. En este sentido, un posible punto de partida lo constituye la afirmación que, en el curso de su ponencia, realizó el profesor Delpech a propósito de que «los datos históricos desempeñan un papel desencadenante» (la cita puede no ser literal, y de cualquier forma la cursiva es nuestra).

4. «Un peu de critique nous fait deviner la légende dans l'histoire. Plus de critique nous fait souvent retrouver l'histoire dans la légende» (Georges CIROT, «Mariana historien», in: Études sur l'historiographie espagnole, Burdeos: Feret et fils, 1905, p. 272). 
motivos $^{5}$. El elemento escogido es lo que podemos denominar «séptuple progenitura», a saber: la condición de ser siete, y hermanos del mismo padre, los héroes de la narración, con el detalle añadido de la «preponderancia del hermano menor». En efecto, hay acuerdo en considerar estos motivos de carácter «legendario», «literario», «mágico», «misterioso»o, en cualquier caso y de modo más general, «folclórico» ${ }^{6}$, términos por lo demás que, cada uno a su manera, no acaban de hacer justicia a los que consideramos que son más bien elementos de naturaleza simbólica, como tendremos oportunidad de exponer más adelante. Es preciso anticipar, en cualquier caso, que el dato de ser siete los infantes de Lara figura en todas las versiones de la leyenda, tanto en las más conocidas (las representadas por las prosificaciones cronísticas) como en otros desarrollos «menores» que la tradición oral ha mantenido prácticamente hasta nuestros días ${ }^{7}$.

5. Es nuestra intención volver en el futuro sobre el texto que nos ocupa de un modo más abarcador, tratando de aplicar la exégesis simbólica sobre el conjunto de la leyenda, y no exclusivamente sobre uno de sus motivos.

6. Sobre el septenario propiamente dicho, vid. Ramón Menéndez Pidal, La leyenda de los infantes de Lara ( $1^{\mathrm{a}}$ ed. 1896), Madrid: Espasa-Calpe, 1971, p. 13, n. 3 («Claro es que el número de siete asignado a los infantes debe de ser legendario») y p. 542 («los hermanos son siete, número mágico»); Julio Escalona Monge, «Épica, crónicas y genealogías. En torno a la historicidad de la leyenda de los infantes de Lara», Cahiers de linguistique hispanique médiévale, 23, 2000, p. 113176, p. 127: «Menéndez Pidal considera (de manera acertada, en mi opinión) que el número de siete para los hijos de Gonzalo Gustioz es de carácter puramente literario»; y Thomas A. LATHROP, The Legend of the "Siete Infantes de Lara»" "Refundición toledana de la Crónica de 1344»version), Chapel Hill: University of North Carolina Press, p. 29 («The oral tradition very quickly raised their number to seven - that magic and mysterious number since biblical times»). Acerca de la «preponderancia del hermano menor», no acertamos a encontrar, en la obra de Menéndez Pidal, el lugar en el que, según T. A. Lathrop (loc. cit.) aquel habría reducido este motivo a razones de exclusiva conveniencia narrativa, en tanto que habría considerado «literary cumbersome for all seven to participate equally in the action, and this is why the youngest, Gonzalo, became the sentimental hero, the heroic spokesman for the rest». Por su parte, el propio Lathrop (loc. cit.) afirma que el protagonismo de Gonzalo González se debe a que, junto con el primogénito Diego, habría sido el único en pasar de hecho por el mundo. La «preponderancia del hermano menor» como folk-motif (al hilo precisamente del menor de los Lara) ha sido estudiada por Alan D. Deyermond y Margaret Chaplin, «Folk-Motifs in the Medieval Spanish epic», Philological Quarterly, 51, 1972, p. 36-53, p. 42-43. Para una sugerente relación de este motivo con «supersticiones» todavía existentes en la mentalidad popular de algunos lugares de Europa, vid. el artículo de Francisco VAz DA SiLvA, «Iberian Seventh-Born Children, Werewolves, and the Dragon Slayer: A Case Study in the Comparative Interpretation of Symbolic Praxis and Fairytales», Folklore, 114, 2003, p. 335-353.

7. En concreto, las referidas al parto múltiple y la Laguna Negra (vid. R. Ménendez PidAL, ibid., p. 485-489, y las remisiones a otras partes del libro), o las que han dejado memoria de los infantes en tierras de Arabiana y Sierra del Almuerzo (ibid., p. 202-203). Para un estudio profundo del motivo del parto múltiple (y en particular séptuple), así como de sus numerosas manifestaciones en la mitología y el folclore indoeuropeos, son de imprescindible consulta los trabajos de François DelPech, «Les jumeaux exclus: cheminements hispaniques d'une mythologie de l'impureté», in: Augustin REDONDo (ed.), Les problèmes de l'exclusion en Espagne (XVI ${ }^{e}$-XVII ${ }^{e}$ siècles), París: Publications de la Sorbonne, 1983, p. 177-203, y «Como puerca en cenegal: remarques sur quelques naissances insolites dans les légendes généalogiques ibériques», in: La condición de la mujer en la Edad Media, Madrid: Universidad Complutense, 1986, p. 343-370. 
Respecto a las versiones épico-cronísticas ${ }^{8}$, en las que, por su mayor elaboración, es posible analizar la función que desempeñan en el relato sus personajes, no es nuevo afirmar que la actuación de los siete hermanos se produce sistemáticamente «en bloque», y que, salvo Gonzalo González (y un tanto el primogénito Diego), los demás hermanos carecen de perfil individualizado, lo que, en su afán historicista, ha llevado a pensar a algún crítico que «in real life» solo existieron esos dos infantes ${ }^{9}$.

Si está, pues, fuera de toda duda la naturaleza ficticia del número de infantes, parece lícito preguntarse el motivo de semejante cifra: ¿por qué siete? Se responderá no sin cierta razón que el septenario está cargado de fuertes connotaciones literarias, poéticas, folclóricas, etc., que favorecen su incorporación a los textos legendarios. Pero la respuesta es poco satisfactoria (en tanto que superficial y apenas esclarecedora), por lo que merece la pena explorar con más detalle los significados que laten en este motivo. Desde luego, ni está a nuestro alcance ni es este el lugar de penetrar a conciencia en el profuso simbolismo del número siete, lo que exigiría setenta veces siete trabajos como este ${ }^{10}$. Tampoco será necesario enumerar la cantidad de septenarios que se encuentran por doquier a nuestro alrededor, tanto en la propia Naturaleza como en la división del tiempo, la arquitectura, la toponimia, las escrituras sagradas, la paremiología o el

Recientemente, el profesor Delpech ha vuelto con renovada intensidad y admirable solvencia sobre el motivo en cuestión (y más genéricamente sobre la mitología septenaria), en varios trabajos ya publicados o en vías de publicación: son, además del que figura en este mismo volumen, las dos partes de «Le cycle des septuplés. Examen de quelques versions folkloriques et hagiographiques celtiques», Boletín de Literatura Oral, 2, 2012, p. 25-54 («Première partie: Les Sept Saints de Bretagne»), y Boletín de Literatura Oral, 3, 2013, p.63-100 («Deuxième partie: légendes pieuses, traditions topographiques et héritage mythique»); y asimismo los inminentes «Figures de l'opposition et traditions généalogiques: la légende portugaise de Maria Mantela», que aparecerá en las actas del coloquio Figures de l'Opposition en Espagne XVI ${ }^{e}-X V I I^{e}$ siècles (París, 2012), y «Mudarra, héros "lughien": remarques sur les coordonées celtiques de la geste des Sept Infants de Lara» (publicado en Atalaya 13, 2013 Vid. http://atalaya.revues.org/927, consultado el 18/01/14), trabajo este último de especial relevancia para lo expuesto en estas líneas. Por lo demás, vid. infra n. 15.

8. No cabe aquí entrar en la cuestión de la prioridad de la versión alfonsí o de la de la Crónica de 1344, aunque, sin haber estudiado a fondo el asunto, nos inclinamos a sugerir que la versión documentada con posterioridad, y por otra parte más rica en elementos simbólicos, presenta una «estructura mítica» suficientemente redonda y ajustada como para que sea innecesario (y aun inconveniente) suponerla fruto de refundiciones tardías de intención «literaturizante». Desde otro punto de vista, así ha sido defendido por J. EscalOnA, art. cit., p. 129-145; posición que, a su vez, ha sido contestada desde posturas más pidalianas por Diego CATALÁn, La épica española, Madrid: Fundación Ramón Menéndez Pidal, 2000, p. 321-324, y especialmente n. 73.

9. Es la opinión de T. A. LATHROP, op. cit., p. 27-30 (la cita corresponde a la p. 27).

10. Una investigación de este tipo puede iniciarse con la consulta de Jean Chevalier y Alain Gheerbrant, Diccionario de los símbolos, Barcelona: Herder, 1986, p.941-947 (s. v. Siete); Hans Biedermann, Diccionario de símbolos (1 ${ }^{\mathrm{a}}$ ed. 1993), Barcelona: Paidós, 2004, p. 423-425 (s. v. Siete), y Juan Eduardo CiRlot, Diccionario de símbolos (1 ${ }^{\text {a }}$ ed. 1969), Madrid: Siruela, 2006, p. 336 (s. v. Números). 
folclore $^{11}$. En todo caso, entre sus funciones más recurrentes, los simbolistas destacan especialmente la de transmitir los significados de totalidad o perfección (más que de mera indefinitud), muy comúnmente aplicados a un término temporal o a un límite espacial ${ }^{12}$. A propósito de esta aplicación espacial del septenario (que será la que más nos interese aquí), cabe recordar la frecuencia con que hallamos la partición en siete de un territorio en relatos o cosmovisiones tradicionales ${ }^{13}$.

11. Una larga lista de las apariciones del septenario en textos de toda índole (y especialmente en el Romancero) puede encontrarse en Eduardo Tejero Robledo, «El siete, número cósmico y sagrado. Su simbología en la cultura y rendimiento en el Romancero», Didáctica (Lengua y Literatura), 15, 2003, p. 221-253. Todavía a propósito del género romancístico y de modo más particular, el reiterado motivo de las circunvalaciones que han de darse alrededor de un espacio carismático ha sido analizado por Samuel G. Armistead y Joseph H. Silverman, «Siete vueltas dio al castillo...», in: En torno al romancero sefardí (hispanismo y balcanismo de la tradición judeo-española), Madrid: Seminario Menéndez Pidal, 1982, p. 105-109, con valiosa bibliografía. Por otro lado, un trabajo de extraordinario interés en el que se vinculan de manera convincente determinadas prácticas consideradas «supersticiosas» ligadas al septenario (en concreto el apadrinamiento del séptimo hijo por parte del hermano mayor de la serie) con el motivo de la «preponderancia del hermano menor» (a menudo en tanto que vencedor del Dragón) tal como nos lo trasmiten algunos cuentos de hadas (por ejemplo, el célebre Pulgarcito) es el de F. VAZ DA Silva, art. cit. Para el tema de la precocidad y fuerza del héroe, en clara desproporción respecto a su tamaño (con mención del mismo cuento), vid. Ananda K. CooMARASWAMY, «Sobre la esposa horrible», en El cuerpo sembrado de ojos, Madrid: Ignitus Ediciones \& Sanz y Torres, 2007, p. 58, n. 10.

12. Vid. J. Chevalier y A. Gheerbrant, op. cit., s. v. Siete, passim. En este trabajo (precisamente por motivos de espacio y tiempo) nos hemos visto obligados a prescindir de la vertiente temporal de la héptada. De cualquier forma, sirva recordar de paso la frecuencia con que se encuentran menciones a periodos de tiempo séptuples en textos tradicionales de toda índole: así, por citar algunos a modo de ejemplo, los siete días de la Creación que propone el Génesis (con su correspondencia analógica en los siete días de la semana), el cese del canto «a la séptima generación» entre los órficos (vid. Alberto Bernabé, «La fórmula órfica "Cerrad las puertas, profanos". Del profano religioso al profano en la materia», 'Ilu. Revista de Ciencias de las Religiones, 1, 1996, p. 13-57) o el ubicuo de «siete años», que lo mismo señala el tiempo de cohabitación del héroe con su amada (Ulises y Calipso en la isla de Ogigia, Tannhäuser y la Dama Venus en Venusberg) que el de la ausencia del esposo sufrida por su mujer (así en algunos romances de tema «odiseico», como La vuelta del marido o La condesita); asimismo, en el romance de La infantina son siete los años que esta permanece «fadada» («hechizada») en una «oscura montiña» (vid. infra n. 14). Diremos, por último, que la división isidoriana de la Historia en seis edades (que remonta a san Agustín e inspira casi toda la historiografía medieval hispánica hasta Alfonso el Sabio) responde en última instancia a un modelo séptuple, en virtud de la identificación de la sexta edad con la época contemporánea al acto de escritura, sentido con frecuencia durante la Edad Media como una época de postrimerías, próxima al fin del mundo, es decir, al fin del ciclo en términos cosmológicos o al periodo de no-manifestación (o sea, a la «séptima edad») en clave metafísica: lo que, a través de la interpretación escatológica de Mateo XX, 1-16 (la parábola de Los obreros de la viña, ritmada en este caso alrededor del número doce), se conoce como «la hora undécima».

13. Valgan de muestra las «fabliellas antiguas» mencionadas por la Estoria de España que suponían un Gerión policéfalo y hacían de él un rey de Hesperia que tiranizaba a los habitantes de las siete provincias de su reino (vid. François Delpech, «Finistères, têtes coupées et monuments talismaniques», Studia Indo-Europea, 1, 2001, p. 171-212, p. 173); o las siete tierras en que está dividido el mundo según la concepción cosmológica de 'Abd al-Karim al-Jîlî (vid. Patrick 
Sin perder de vista estas ideas, nuestro intento será el de centrarnos en la mencionada séptuple progenitura, y buscar otros casos de «siete hijos» en mitos, leyendas, cuentos o creencias. Ciertamente, se trata todavía de un motivo sumamente frecuente en el folclore universal, de modo que emprenderemos su análisis sin posible esperanza de exhaustividad. En primer término, y como ensayo tipológico de este motivo, observamos que en ocasiones los relatos inciden más bien en la condición de ser siete los hermanos del héroe o la heroína ${ }^{14}$; a veces, la relación se establece más estrechamente entre los hijos y la madre ${ }^{15}$, y otras entre los hijos y el padre, sin faltar casos de doble septenario: siete hijos y siete hijas ${ }^{16}$. Por otra parte, un motivo adicional que, como ya hemos señalado, aparece a menudo en el caso de la séptuple progenitura es el de la preponderancia

Franke, Begegnung mit Khidr, Stuttgart: Steiner, 2000, p. 207-208). El motivo tiene su reflejo en determinadas concepciones políticas tradicionales, por ejemplo, la de la realeza irania, a cuyo monarca se le denominaba «Señor de los Siete Países» (vid. Jean Hani, La realeza sagrada. Del faraón al cristianísimo rey, Palma de Mallorca: Olañeta, 1998, p. 57), y es probable que haya influido incluso en la división de Euskal Herria en siete territorios tal como fue difundida por el primer nacionalismo vasco a través de la divisa «Zazpiak Bat» («las siete en una»).

14. Es el caso de los siete duques-hermanos que se llevan a la protagonista en algunas versiones del célebre romance de La infantina (en concreto, en las de la tradición oral moderna recogida entre los sefardíes de Marruecos): «Siete duques la llevaban / y un rey, que más valía: / su padre y sus siete hermanos, / que en su busquedad venían» (vid. Susana WeichShahak y Paloma Díaz-Mas, Romancero sefardí de Marruecos, Madrid: Alpuerto, 1997, p. 171172). Digamos de paso que este romance en particular es especialmente profuso en el uso del septenario: «Siete hadas me fadaron / en haldas de mi madrina, / que anduviese siete años / en esta oscura montiña $[\ldots] »$.

15. Es de señalar que abunda en este caso la circunstancia de morir los siete hijos por intervención más o menos directa de la madre. En este sentido, el folclore argentino recoge la leyenda del Suindá, un pájaro de mal agüero en el que se convirtió una joven costurera cuyos hijos murieron de frío por su negligencia (relato que parece mantener alguna relación con el celebérrimo de la Llorona, también madre asesina de siete hijos en algunas versiones). Además, encontramos al menos dos leyendas hagiográficas que hacen de sendas madres de siete hijos (santa Felicitas y santa Sinforosa) dos víctimas del martirio por negarse a claudicar de su fe, seguidas de inmediato por el sacrificio de sus respectivas descendencias. De algún modo emparentadas con estos relatos (aunque sin que ocurra la muerte de los hijos) están las variantes de la leyenda de los infantes de Lara que hablan de un parto múltiple y de un subsiguiente abandono materno, que ya Menéndez Pidal recogió de boca de la guardesa del monasterio de Arlanza a finales del siglo xix (R. Menéndez Pidal, op. cit., p. 182-183), y que ha mantenido vitalidad oral durante el siglo xx (ibid., p. 202-203 y 485-486). Se trata del mismo relato que desde antiguo se cuenta respecto al origen del linaje de los Porceles (ibid., p. 486-488) o, todavía en la actualidad, a propósito del de las localidades de Castelo dos Sete Infantes (Lugo; vid. Leandro Carré Alvarellos, Las leyendas tradicionales gallegas, Madrid: Espasa-Calpe, 1978, p. 258-260) y de Soto de los Infantes (Asturias). En él se expresa la crueldad de una madre de septillizos que ordena hacer desaparecer a seis de ellos, siendo descubierta por el padre y, transcurrido el tiempo, sometida a la prueba de reconocer cuál de ellos es «su hijo». En torno a esta proteica y fecunda narración, vid. los trabajos de François Delpech citados en la n. 7.

16. La mitología griega recoge el caso de Níobe, esposa de Anfión, cuya extraordinaria fecundidad la llevó a burlarse de Leto, que solo había engendrado a Apolo y Ártemis. Estos volcaron sobre ella su venganza, matando a casi todos sus hijos. Su cuerpo fue convertido en roca y sus lágrimas en manantial. 
del hermano menor ${ }^{17}$, que retendremos por su relevancia para la trama de nuestra leyenda ${ }^{18}$. Pero de todas las variantes existentes de séptuple progenitura, queremos enfocar la atención, tanto por remitir al citado simbolismo espacial del número siete como por sus posibilidades de aplicación al caso de los infantes de Lara, hacia la de los «siete hijos fundadores» o, en cualquier caso, asociados a la soberanía de un territorio. En efecto, este submotivo parece responder a un modelo mítico relativamente generalizado, toda vez que lo encontramos, recreado con mayor o menor detalle y diversidad de desarrollos, en tradiciones muy distantes en el espacio y en el tiempo.

Por ejemplo, según nos transmite Píndaro en la Olímpica VII ${ }^{19}$, ausente Helios-Sol del primer reparto de la Tierra, nadie se acordó entonces de dotarle de alguna porción de ella, de modo que Zeus le propone una nueva distribución; sin embargo, el Sol se niega a aceptarla, pues afirma ver en ese mismo instante cómo surge del mar «una tierra feraz para los hombres / y para los rebaños generosa», a saber, la isla de Rodas (que en el desarrollo del mito es también su epónima, la ninfa Rodo); concedido el deseo de serle atribuida, se une con ella y engendra a los siete helíadas, todos los cuales heredaron de él espíritus aún más sabios que los de los héroes antiguos y fueron tenidos por excelentes astrólogos. Tres de sus descendientes (Cámiro, Yáliso y Lindo, hijos del primogénito Óquimo) acabarán por dividirse la tierra de su padre y por imponer su nombre a las tres ciudades de Rodas.

Un llamativo paralelo hispánico del antiguo mito griego lo encontramos en los folios $197 \mathrm{v}^{\circ}$ y $198 \mathrm{r}^{\circ}$ del célebre códice de Roda (copiado probablemente por un monje del scriptorium emilianense en la Nájera de los siglos X y XI, y hoy en la Biblioteca de la Real Academia de la Historia, cód. 78$)^{20}$;

17. Así ocurre, por citar un par de casos, en la Leyenda del pozo airón tal como la conserva el romance de la tradición sefardí «Ya se van los siete hermanos...» (donde «al más chico le cayó» en gracia el descensus ad inferos correspondiente), o en el conocidísimo de La doncella guerrera, en el que es «la más chiquitica» de las hijas la que siente la inclinación de ir a la guerra «vestidita de varón». Fuera del romancero, también el menor de siete hermanos es el citado Pulgarcito del cuento infantil homónimo o el protagonista de Los siete cabritillos. Añadamos que el motivo genérico es el formulado por Stith THOMPSON como victorious youngest son (L10 sqq) en su Motif-Index of Folk Literature. A Classification of Narrative Elements in Folktales, Ballads, Myths, Fables, Mediaeval Romances, Exempla, Fabliaux, Fest-Books and Local Legends, Bloomington: Indiana University Press, 1955-1958.

18. La primacía del hermano menor sobre el resto, especialmente en términos hereditarios, ha sido analizada por J. Escalona Monge, art. cit., p. 140-141, siguiendo las ideas de Abilio Barbero de Aguilera y Marcelo Vigil Pascual, La formación del feudalismo en la Península Ibérica, Barcelona: Crítica, 1978, p. 398-399. Para una interpretación del motivo, ligada a ciertas creencias populares paneuropeas sobre el nacimiento de un séptimo hijo, vid. F. VAZ DA SILVA, art. cit.

19. Píndaro, Odas triunfales, ed. José Alsina, Barcelona: Planeta, 1990, p.42-43.

20. Hasta donde sabemos, esta vinculación no ha sido señalada, ni tampoco la naturaleza simbólica del texto. Contamos, eso sí, con las opiniones de Juan Gil y de Manuel C. Díaz y Díaz, 
allí figura la que podemos denominar Leyenda de Septemsídero, un curioso texto que, traducido del original latino, reza como sigue:

La ciudad de Toledo fue la primera fundada en Hispania, y le están sometidas todas las ciudades hispanas. Hubo en Toledo un rey, llamado Octaviano, cuando aún Lugo, Astorga, León, Zamora, Braga, Chaves, Oporto, Tuy no estaban construidas. Mandó llamar Octaviano a Septemsídero, marido de [Iberia], padre de Brácaro y de Flavio y de Teodorico y de Galaa y de Gémulo y de Cesario, el que construyó Cesarea y [¿el?] Faro. Y no quiso Septemsídero ir a ver al rey Octaviano, e hizo Octaviano una gran campaña y marchó contra Septemsídero, e hizo acampar su hueste en el sitio llamado Sumio. Y llegó allí Septemsídero e hizo acampar sus huestes, y oró a Dios, y fueron aniquiladas las huestes de Octaviano y perdieron la vida; por esto fue llamado aquel lugar Sumio. Y fue Septemsídero con su mujer y sus hijos a la ciudad [?] de Lugo y [¿̇mandó?] a cada uno de sus hijos a una ciudad: Brácaro a Braga, Flavio a Chaves, Teuderico a Tuy, a orillas del mar, Galaa a Portugal; Secuario fue muerto en el Tambre en el lugar que dicen Puerto Sigüeiro; Gémulo era forzudo, en cada mano podía llevar un par de columnas. Él hizo la bóveda de San Pedro y Celbas [¿o Celas?], arriba de Caldas, y un puente en el Miño. Y Cesáreo ya ha sido citado. Y de otras ciudades sería mucho hablar ${ }^{21}$.

En efecto, los motivos estructurales de este relato parecen similares a los del mito griego, a saber: por un lado, el héroe-padre, cuyo nombre (Septemsídero) transparenta un nítido «Siete-estrellas» ${ }^{22}$ (que Juan Gil traduce por «Siete-planetas» ${ }^{23}$, y en el que, en todo caso, reconoce «resabios astrológicos evidentes»), un personaje que recuerda enormemente al

expuestas en sendos comentarios a sus casi coetáneas ediciones del texto (respectivamente en «Textos olvidados del códice de Roda», Habis, 2, 1971, p. 165-178, p. 165-170; y en «Tres ciudades en el códice de Roda: Babilonia, Nínive y Toledo», Archivo Español de Arqueología, 45-47, 19721974, p. 251-265, p. 256 y 258-263). Para completar la bibliografía sobre este opúsculo, añádase, al primer artículo, la «Nota adicional al trabajo del prof. Juan Gil» a cargo de Isidoro MiLLÁN GonzÁlez-PARdo (Habis, 2, 1971, p. 179-181), y al segundo, las p. 101-106 de Visiones del más allá en Galicia durante la alta Edad Media, Santiago de Compostela: s. n., 1985, del propio M. C. Díaz y Díaz (esta vez con traducción incluida). Por lo demás, Juan Gil propuso como posible motivación última del «ingenuo falsificador» autor de nuestro texto la exaltación de la iglesia gallega (fundada en el prestigio del culto jacobeo), por medio de la victoria de un héroe local sobre un rey de Toledo (a la sazón, primada de las Españas y única sede que podía competir con Santiago) llamado Octaviano, antropónimo de sonoridad imperial, que acabaría por dejar a Compostela por encima de la propia Roma. Por su parte, Díaz y Díaz cree encontrar en el relato más bien resonancias de las disputas, frecuentes durante el siglo x, entre las jurisdicciones eclesiásticas de Lugo y Braga, a la vez que interpreta el enfrentamiento entre Septemsídero y Octaviano (en el que, por cierto, cabría ver una oposición numerológica intencionada) como un eco de la leyenda de la destrucción de España. Por último, añadamos que el texto, sembrado de topónimos, se ha prestado al debate sobre la localización real de esa «geografía legendaria».

21. La traducción, con sus dudas (y salvo Iberia, que es conjetura nuestra; vid. infra y n. 26), es de M. C. Díaz y Díaz, Visiones del más allá..., p. 102-103).

22. Como ya advierte M. C. Díaz y Díaz, ibid., p. 103, n. 150.

23. Se trata, en efecto, de los siete planetas o «estrellas errantes», en oposición a las «estrellas fijas» o constelaciones, ubicadas en la octava esfera. 
Helios-Sol del mito antiguo ${ }^{24}$; por otro, esos «siete» hijos a los que forzosamente remite el antropónimo paterno, fundadores de ciudades o constructores en el noroeste peninsular ${ }^{25}$. Además, la madre de los héroes es nombrada en el códice de Roda como Iherie, lectura que, para Juan Gil, es probablemente error por Iberie, «con fácil confusión de $b$ y $h$ en la minúscula visigótica» ${ }^{26}$, conjetura esta que encaja a la perfección con el esquema legendario: en efecto, Iberia (como Rodas) es aquí (ya lo veremos) imagen de la Tierra a la que el Sol fecunda.

Otros ecos de este modelo mítico, más difusos y descargados de motivos, parecen no obstante poder distinguirse en diversas narraciones de muy distinto origen, en las cuales permanece siempre, al menos, el tema central del padre y sus siete hijos fundadores, constructores o, en general, ligados a la soberanía u ordenación de un territorio. Así ocurre, por ejemplo, con la leyenda local que narra el origen del municipio pirenaico de Setcases («Sietecasas »):

Una familia de ganaderos (un padre y sus siete hijos, que no habían subido nunca a la montaña) se paró en el Pla dels Hospitalets para que las ovejas pacieran. Al cabo de dos días, empezó a nevar, y los hijos se quedaron maravillados porque no habían visto nunca aquellos copos blancos. Corrieron a decírselo al padre, que era ciego. El padre les explicó que aquello era nieve, que llegaría a cubrir toda la hierba y que las ovejas se morirían de hambre. A continuación empezaron el descenso, y el padre decidió que se quedarían donde encontraran un saúco florido. Yendo hacia abajo, pasaron el valle del Carlat y, al cabo de un rato, vieron una flor de saúco, y allí se quedaron. El lugar era placentero y cada uno de los hijos construyó su cabaña. Por eso, el pueblo que creció en el entorno de las primeras cabañas se conoce hoy con el nombre de Setcases ${ }^{27}$.

24. Significativamente, Septemsídero distribuye a sus hijos desde Lugo, topónimo que se ha hecho remontar al nombre del dios solar Lug. En este sentido, ya M. C. DíAz y DíAz, «Tres ciudades en el códice de Roda...», p. 258) subraya «la presencia destacada de Lugo, que parece ofrecerse como la ciudad más importante de la nómina $[\ldots]$ ».

25. M. C. DíAz y DíAz, Visiones del más allá..., p. 103, n. 150, ya asume la correspondencia entre hijos y estrellas. Sin embargo, hay motivos (tanto filológicos como simbólicos) para pensar que no son siete, sino seis, los hijos de Septemsídero (como sugiere la primera de las listas que de ellos se aporta) y que en el septenario resultante ha de incluirse al propio padre, lo que lo equipararía más nítidamente con la figura del Sol. Otra posibilidad es computar como doble, en atención a su nombre, a Gemulus ( gemellus, «gemelo»), duplicidad que también parece venir sugerida por su capacidad de transportar dos columnas en cada una de sus dos manos (F. DeLPECH, «Les jumeaux exclus...», ha profundizado en la estrecha relación existente entre la gemelitud doble y la séptuple, que en este relato aparecerían reunidas; llamativamente, lo mismo ocurre en la Leyenda de los infantes de Lara, en virtud de la asimilación operada entre Gonzalo González y su hermanastro Mudarra en la versión más amplia del relato; vid. infra n. 34). En cualquier caso, tenemos previsto consagrar a este texto rotense un trabajo donde tratar esta y otras cuestiones colindantes.

26. J. Gil, art. cit., p. 166. Por su parte, M. C. Díaz y DíAz, ibid., p. 102, traduce «Egeria».

27. Este texto fue extraído (y consultado por última vez hacia el otoño de 2011 ) de la página web del ayuntamiento de Setcases [http://www.setcases.info/esp/llegenda.html], que hoy (junio de 2013) ya «no se encuentra». Por lo demás, la cursiva es nuestra. 
Existen más testimonios, entre los que citaremos (aunque ahora no podemos detenernos en su desarrollo y con la seguridad de que no han de ser los únicos), por ejemplo, el del patriarca bíblico Jafet (hijo de Noé), a cuyos siete hijos hace Josefo en sus Antiquitates Judaicae I.6 (glosando Gn X, 2) fundadores epónimos de sendos pueblos euroasiáticos ${ }^{28}$; o los siete hijos de Míl Espáine (hijo a su vez de Breogan), quienes, según el Lebor Gabála Érenn (o Libro de las invasiones de Irlanda), protagonizaron la conquista gaélica de la isla $^{29}$. Conquistadores de territorios son también los siete hijos de Aymerí de Narbona, conforme narran los cantares de gesta franceses dedicados a este héroe y a su progenie (cuya posible vinculación con los de Lara ya ha sido señalada $)^{30}$. Mucho antes, en el poema acadio de contenido cosmogónico Atrahasis (s. XVIII a. C.), son siete hombres y siete mujeres los fundadores del linaje humano, a cuyo cargo queda la población de la Tierra ${ }^{31}$. Otro caso que nos parece asimilable (por ser el héroe epónimo miembro de un septenario) es el que narra una de las leyendas del origen de la etnia centroafricana Kakwa, donde se afirma que descienden de Yeki, uno de cuyos siete hijos tenía por costumbre morder a sus hermanos, por lo que Yeki le apodó Kakwanji («Mordedor»), sobrenombre que, en plural, adoptaron a la postre los descendientes de Yeki ${ }^{32}$. Añadamos finalmente (por su especial relevancia para la Leyenda de los infantes de Lara) que una prolongación de las funciones de conquista o fundación ha de ser la de la bondad de los siete hijos en el ejercicio de las armas. En este sentido, una leyenda genealógica transmitida por Argote de Molina (a través de una carta que Antonio de Barahona «escrivió a don Martín Sánchez de Xódar, chantre de Baeza, en el año de mil y quatrocientos y noventa y nueve de los linajes

28. «En efecto, Jafet, hijo de Noé, tuvo siete hijos. Estos empezaron por habitar tierras desde los montes Tauro y Amano, para llegar en Asia hasta el río Tanais y en Europa hasta Cádiz, ocupando las tierras que encontraban a su paso y, como nadie había habitado antes esos lugares, designaron a esos pueblos con sus propios nombres [...]»; FLAVIO Josefo, Antigüedades judías. Libros I-IX (1 ${ }^{\text {a }}$ ed. 1997), ed. José VAra Donado, Madrid: Akal, 2009, p. 41.

29. Vid. Lebor Gabála Érenn: The Book of the Taking of Ireland. Part V, ed. y trad. Robert AlexAnder, Dublín: Irish Texts Society, 1956, p. 21-25. Hay traducción al español en Lebor Gabála: libro de las invasiones de Irlanda, ed. y trad. Manuel Alberro, Gijón: Trea, 2007.

30. Martín DE RiQuer, Historia de la literatura universal, Barcelona: Planeta, 1984, p. 162. Por otra parte, en el curso de su ponencia en el congreso de Salas, el profesor Delpech aludió a un septenario vinculado asimismo al ciclo épico de Renaud de Montauban; consultado posteriormente por nosotros sobre el particular, su respuesta fue la siguiente: «[...] los hijos de Aymon son 4, pero en la secuencia de la visita a su madre son acompañados por 3 caballeros (a quienes la madre recibe casi en plan de igualdad con sus 4 hijos). Me pregunto si será reminiscencia de alguna forma primitiva de la leyenda en la que serían 7 los protagonistas (?)» (carta fechada en París, 8/1/2012).

31. Vid. Wilfred G. Lambert y Alan R. Millard, Atra-hasīs: The Babylonian Story of the Flood, Oxford: University Press, 1969.

32. Wairama G. BAKER, Uganda: The Marginalization of Minorities, Londres: Minority Rights Group International, 2001, p. 30, n. 15. 
de aquella ciudad») explica el origen del solar de los Garrido contando que procede de un noble caballero conocido como «Diosayuda» (antropónimo altamente significativo), que con sus siete hijos sirvió brillantemente al rey Alfonso XI en la batalla del Salado, quien, al verlos desfilar tras la victoria con las armas ensangrentadas, no tuvo por menos que decir: «Garridos hijos lleváis», de donde su sobrenombre ${ }^{33}$. En este caso, la fundación no lo es tanto de un territorio cuanto de un linaje, lo que en última instancia no hay duda de que viene a ser lo mismo.

En todos estos ejemplos, como anticipábamos, creemos poder distinguir un único modelo mítico subyacente, y que, grosso modo, vincula la existencia de siete hijos con la noción de apropiación, soberanía y, especialmente, ordenación del espacio, a través de su fundación, su conquista, su construcción, su denominación epónima, etc., en virtud de lo cual podemos designar este submodelo como «séptuple progenitura fundadora». Las variantes más desarrolladas (y más «fieles», pensamos, al sentido original del mito) relatan la procreación de siete hijos por la unión de una divinidad solar (más o menos humanizada) con la Tierra (o con una mujer vinculada a ella estrechamente), descendencia que acaba fundando un territorio.

\section{La hebdómada de Lara como avatar de séptuple progenitura fundadora}

Si aceptamos que, en efecto, debajo de estas narraciones late un mismo esquema mítico, cabe preguntarse, de vuelta sobre nuestra leyenda, en qué medida podría aplicársele a la de los siete infantes de Lara. Cierto que, en las versiones que conocemos, estos no son en rigor fundadores o conquistadores de un territorio (cuya existencia como tal les precede), pero no lo es menos que, por una parte, no habrá que insistir más que Gonzalo Gustios delante de las cabezas de sus hijos en las «buenas mañas» de estos como caballeros de armas (lo que también revela el desarrollo de las prosificaciones cronísticas), y acabamos de señalar (a propósito de la leyenda genealógica de los Garrido) que es esta una prolongación natural de las funciones de conquista o fundación. Por otra, a pesar de no existir noticia fundacional explícita, reducida la trama a su mínima expresión, lo que se nos relata es un episodio en la línea sucesoria de un linaje; digamos, una re-fundación de un clan familiar, tras la violenta desaparición de sus siete descendientes naturales, en la figura de un único sucesor, el vengador Mudarra, que se erige así en cabeza de la renovada estirpe ${ }^{34}$. Además de

33. Gonzalo Argote de Molina, Nobleza del Andaluzía, Sevilla: Fernando Díaz, 1588, p. 205.

34. En este sentido, vid. J. Chevalier y A. Gheerbrant, op. cit., p. 942: «Siete designa el sentido de un cambio después de un ciclo consumado y de una renovación positiva». Por su 
lo dicho, llama la atención el empeño «antihistoricista» que ha mantenido la tradición a la hora de conceder el título de «infantes» a nuestros héroes (a pesar de no serlo técnicamente, pues, como es sabido, solo lo son los hijos de los reyes), y ello para perplejidad de la erudición secular ${ }^{35}$. Sin ser este un argumento concluyente, lo cierto es que, desde la perspectiva simbólica que venimos adoptando (y en particular desde el modelo mítico que hemos analizado), se explicaría bien esta denominación, toda vez que podría sustentarse sobre la consabida asociación entre la figura del monarca y la del astro-rey ${ }^{36}$. Respecto a la vinculación de la madre de los siete héroes (doña Sancha en este caso) con nociones ligadas al simbolismo de la Tierra, nos parece relevante recordar los comentarios de Julio Escalona y de Mercedes Vaquero a propósito del contexto matrilineal en que estaría inmerso el germen de la leyenda ${ }^{37}$. En efecto, episodios como el de la profiliación de Mudarra y otros detalles narrativos estudiados por estos autores sugieren la preponderancia femenina en la transmisión hereditaria del linaje, es decir, del solar al que están asociados los héroes.

Pues bien: creemos que todos estos ecos legitiman la inclusión del septenario burgalés en el conjunto de los pertenecientes al modelo mítico señalado, si bien diluido en los desarrollos mucho más elaborados que encontró la leyenda en su adopción por parte de los géneros épico e historiográfico. Y el caso es que para este modelo (y en particular para el que podemos considerar su cabecera, el mito de Helios y la ninfa Rodo),

parte, el profesor Delpech sugirió también (en el curso de su ponencia) la interpretación de la muerte de los siete infantes y el nacimiento de Mudarra en clave escatológica (como destrucción y renacimiento de un linaje, vale decir: de un mundo). A nuestro juicio, y en relación con el motivo fundacional, no ha de perderse de vista tampoco el componente cosmogónico de la secuencia (que, por lo demás, late en el escatológico por coincidentia oppositorum), en virtud ante todo de la clara «continuidad genética» que la leyenda establece entre los siete infantes y Mudarra (quien no hubiera existido sin la muerte de sus hermanos), sobre todo a través de la práctica identificación entre Gonzalo y el bastardo en la que tan explícitamente incide la versión de la Crónica de 1344. A propósito de este elemento cosmogónico, vid. precisamente F. DeLPech, «Como puerca en cenegal...», p. 365 y n. 84. Para la asimilación Gonzalo González = Mudarra y su consideración como motivo folclórico (junto a otros asociados a la figura del bastardo), vid. A. D. Deyermond y M. ChaPLIN, art. cit., p. 42-43; es relevante notar que, para estos autores, el triunfo de Mudarra remitiría al motivo E234 (Return from the dead to avenge murder), lo que equivale a aceptar esa asimilación tan evidente. Por lo demás, y en función del eventual dioscurismo que pueda latir en esta pareja, hay indicios para pensar que una indagación en torno al vínculo entre la héptada y la gemelitud (implícito asimismo en la Leyenda de Septemsídero; vid. supra n. 25) ofrezca resultados relevantes. Por fin, cabe mencionar de pasada que en toda esta cuestión ha de jugar un papel decisivo el seguro componente sacrificial que subyace en la muerte de los infantes.

35. Vid. R. MenÉndez Pidal, op. cit., p. 442-443.

36. Para el simbolismo solar de la soberanía regia desde una perspectiva comparada, vid. J. HANI, op. cit., p. 20, 37, 50, 59, 161-163 y 197-199.

37. J. Escalona Monge, art. cit., p. 139-145, y Mercedes Vaquero, La mujer en la épica castellano-leonesa en su contexto histórico, México D. F.: Universidad Nacional Autónoma de México, 2005, p. 86 sqq. 
creemos hallar estrechos paralelos en determinado simbolismo de orden sagrado (y por ello de alcance, en definitiva, metafísico), que, de aceptarse, cabría extender al resto de sus avatares, y en particular a nuestra leyenda ${ }^{38}$.

\section{Aproximación al simbolismo de la séptuple progenitura fundadora}

En efecto, afirma con razón François Delpech que la amplia serie de leyendas protagonizadas por siete gemelos (y más genéricamente, añadimos, por siete hermanos) «mériterait également une étude comparative qui devrait se situer à la fois sur le plan du folklore narratif, de l'histoire des religions et de représentations astronomiques» ${ }^{39}$, como por lo demás sugieren los mitos hindúes de los siete Aditias, o de los respectivos nacimientos de los siete Marut y del dios Skanda ${ }^{40}$, o bien la leyenda cristiana de los Siete Durmientes de Éfeso (aludida también en la célebre sura al-Kahf del Corán), o la de los Siete Santos fundadores de Bretaña, todos ellos relatos citados por el autor ${ }^{41}$.

38. Ello no ha de extrañar demasiado al menos en el caso del mito griego, donde significados de este tipo pueden apreciarse mejor en la medida en que tratamos en él directamente con dioses. En este sentido, valga la afirmación de F. VAZ DE SILvA, art. cit., p. 335, para quien son «fundamental concepts of a metaphysical sort» los que informan (aparte de costumbres y ritos, de creencias y supersticiones) el folclore narrativo. Desarrollos mucho más amplios de esta concepción del folclore (así como ejemplos de la praxis exegética que lleva aparejada) se encontrarán en algunos trabajos de varios de los miembros de la que, en el contexto de los «estudios espirituales», se conoce como «escuela tradicional» (por remitirse a una Tradición universal - también llamada «unánime» $\mathrm{o}$ «perenne» - de la que todas las formas espirituales de la humanidad se consideran manifestaciones particulares, y por ello asimilables). Valga citar, a título ilustrativo, las siguientes referencias: René GuÉNOn, Símbolos fundamentales de la ciencia sagrada, Madrid: Paidós, 1995; A. K. Coomaraswamy, El cuerpo sembrado de ojos, Madrid: Ignitus Ediciones \& Sanz y Torres, 2007; y Jean Hani, Ritos, mitos y simbolos. Los caminos hacia lo invisible ( $1^{\text {a }}$ ed. 1999), Palma de Mallorca: Olañeta, 2005. Conviene añadir que las propuestas de estos autores se asientan sobre una noción de símbolo muy delimitada y precisa, que en última instancia se atiene a la condición de ser este un soporte (físico) de contemplación (metafísica).

39. F. Delpech, «Como puerca en cenegal...», p. 366. En «Les jumeaux exclus...», p. 194, n. 81, afirma asimismo: «Nombres de légendes locales, de contes populaires et de traiditions mythiques et épiques évoquent des séries de sept frères [...]. La plupart de ces récits comportent un scénario d'expulsion et/ou de sacrifice. Le dossier est complexe: le septenaire est tour à tour lié à des conceptions cosmogoniques, astrologiques (la Grande Ourse, les Pléiades, etc.), initiaques [...]». Consúltense estos dos trabajos para conocer otros desarrollos de la fratría séptuple (leyendas de los Porceles de Murcia, de los Enfants-cygnes, cuento de Los siete cuervos, etc.), y ahora el resto de los citados supra (n. 7), que aumentan extraordinariamente la nómina de narraciones septenarias vinculadas entre sí (relatos locales armoricanos, tradiciones hagiográficas, respectivas leyendas de Los Siete Santos de Bretaña, Los Siete Durmientes de Éfeso, la portuguesa de María Mantela, etc.) y que asimismo ahondan de manera magistral en su transmisión, naturaleza y sentido.

40. Sobre los Marut en relación con los Siete Soplos (vid. infra n. 46), vid. A. K. CoomARASWAMY, «Sobre la psicología india y tradicional, mejor llamada pneumatología», in: El vedanta y la tradición occidental, Madrid: Siruela, 2001, p.307-363, p. 342-344.

41. Esperamos con entusiasmo su monografia sobre las héptadas (de que son entregas parciales los artículos citados en la n. 7), en la que, según comunicación personal por su parte, se 
Por nuestra parte, creemos que un estudio de este tipo no puede prescindir (de hecho quizá debiera partir) de las analogías detectables entre el simbolismo cosmológico de los Siete Rayos solares (tal como nos lo transmite la tradición védica) y el modelo mítico analizado (en tanto que reducible a la fórmula: Sol-padre + Tierra-madre $=$ siete hijos «materializadores»), que en efecto parece traducir aquel en clave narrativa. Ciertamente, la irradiación luminosa que le es propia al símbolo de los rayos solares tiene por función extraer el «orden» a partir del «caos» (entendido este como principio pasivo o substancial de la existencia, correspondiente a su polo tenebroso, vale también decir «femenino»); en términos metafisicos, pues, los rayos solares «producen la manifestación» ${ }^{42}$. Pues bien, semejante función «manifestadora» consideramos que, en virtud de las analogías simbólicas correspondientes, se equipara enteramente a la «ordenación del espacio» que, como hemos observado, es característica de la séptuple progenitura fundadora ${ }^{43}$. En este sentido, cabe añadir que la doctrina de los Siete Rayos se encuentra en la tradición védica asociada a los de la divinidad solar Agni, y formulada en ocasiones de forma explícita como la de los «siete hijos del Sol», lo que la aproxima extraordinariamente

abordarán con mayor profundidad los aspectos célticos del asunto y su enlace con la mitología «cabírica», que se puede detectar hasta en la leyenda portuguesa de Los aventureros de Lisboa o en los relatos sobre los Siete Santos de Marrakech. Nos preguntamos si al elenco de septenarios sagrados no cabría añadir otros, como, al menos, los de los Siete Arcángeles de la angelología tradicional, los Siete Amshaspendas mazdeos o los Siete Espíritus del Libro de los muertos egipcio. En este sentido, José Antonio Antón Pacheco, El Ser y los símbolos, Tarragona: Mandala, 2010, p. 381, ha llamado la atención asimismo sobre «los siete brazos del candelabro en Filón; los siete Keshvars (climas o regiones arquetípicas) del mazdeísmo; la Hebdómada sagrada o pléroma de las siete hipóstasis arcangélicas de los sistemas gnósticos, ismaelitas, etc.» (en las p. 234-236 de esta misma obra, el autor estudia la correspondencia analógica entre los símbolos del árbol, la escala, los pájaros-ángel y la propia interioridad del hombre, en cuya aplicación séptuple ve una «imagen típica tanto del proceso ascensional de iniciación como de la vía religadora»). Las implicaciones simbólicas de la héptada en textos y cosmovisiones sagrados admite desarrollos mucho más amplios a la vista de su relevancia en casos como el del Apocalipsis de Juan o el chiísmo ismailí o septimano (para este último, vid. Henry Corbin, «La profetología ismailiı, in: El imam oculto, Madrid: Losada, 2005, p. 49-77).

42. «Los rayos solares revelan las cosas que iluminan, las hacen visibles y por tanto pueden supuestamente "manifestarlas"» (R. GuÉNON, El reino de la cantidad y los signos de los tiempos, Madrid: Paidós, 1997, p. 31, donde se exponen las implicaciones puramente metafísicas del simbolismo en cuestión).

43. Lo que se aprecia nítidamente a través de la asimilación del mito védico de los Rbhus con el simbolismo de los siete rayos solares, tal como la expone A. K. CoOmaraswamy en su trabajo «El simbolismo del domo», in: El cuerpo sembrado..., p. 140-212 (especialmente p. 142149), pues la división de la copa del Titán operada por los protagonistas del mito se refiere «al acto de creación primordial por el que se prepara un "lugar" [...]», y la expresión védica con que se describe tal acto (vi mamuh < vi mā " "medir", "trazar") puede asumir los significados de "planificar" e incluso "construir" y «aparece en el Rg Veda principalmente en conexión con la determinación creativa del "espacio" [...]» (p. 142). 
a las que proponemos como su adecuado reflejo literario ${ }^{44}$. Por lo demás, tal concepción cosmológica se encuentra asimismo en la base de la iconografía de la rueda de seis radios y de la cruz de tres dimensiones y, por tanto, de seis direcciones o brazos, cuyo «séptimo rayo» no es otro que el centro mismo, símbolos estos últimos que es preciso identificar respectivamente con los del axis mundi y la Puerta del Sol (o fanua coeli) ${ }^{45}$. Este rayo central, al que los vedas denominan «séptimo y mejor», creemos que ha de corresponder con la preponderancia del hermano menor que hemos señalado en algunas formulaciones narrativas del mito (cuyo carácter solar, por cierto, a menudo apoyan determinados detalles argumentales ${ }^{46}$. En fin, las implicaciones cosmogónicas de esta doctrina (es decir, su aspecto de acto creativo primordial por determinación en el tiempo y, lo que más nos ha importado, en el espacio) encajan a la perfección con las nociones del mismo tipo que hemos hallado en el motivo de la séptuple progenitura fundadora, y parecen a tal punto inherentes al simbolismo del septenario que estamos tentados de afirmar, con Clemente de Alejandría, que «ese es el secreto del número Siete» ${ }^{47}$.

En conclusión, si en la Leyenda de los infantes de Lara, por encima de los detalles historicistas que la sitúan en un tiempo y un lugar determinados; por encima de su interés al parecer en principio exclusivamente local; e incluso por encima del consabido «realismo» de la épica española, es posible

44. Para la doctrina de los Siete Rayos de Agni o del Sol (así como para los loci védicos donde se les designa como «sus hijos»), vid. id., «Rigveda 10.90.1 áty atishthad dasângulám», n. 37 (y texto correspondiente), in: Sobre la traducción, Madrid: Ignitus Ediciones \& Sanz y Torres, 2007. Por otra parte, están por explorar las implicaciones simbólicas del extendidísimo cuento tradicional conocido como La hija del diablo, en algunas de cuyas versiones hispánicas la protagonista se llama Siete Rayos de Sol (o Marisoles); vid. Aurelio M. Espinosa, Cuentos populares españoles, 3 vol., California: Stanford University, 1924, p. 240 y sqq.

45. Para todo ello, vid. A. K. Coomaraswamy, «El simbolismo del domo», p. 140-212 (en especial, p. 147-149 y n. 11) e id., «Simplégades», in: El cuerpo sembrado..., p. 285-319, p. 315-316 y n. 48. Para el simbolismo específico de la Puerta del Sol, vid., del mismo, «Svayamātrnna: Janua Coeli», in: El cuerpo sembrado..., p. 213-284. Vid., además, de R. GuÉnOn, «La puerta estrecha» y «Los siete rayos y el arco iris», in: Símbolos fundamentales..., p. 202-204 y 258-261, respectivamente.

46. Otras representaciones simbólicas de este «séptimo rayo y mejor» se traen a colación en A. K. Coomaraswamy, «Svayamātrnna...», p. 261-262, n. 65, e id., «Simplégades», p. 299, n. 22. Por otro lado, la doctrina de los Siete Rayos presenta aplicaciones analógicas diversas, que afectan a formulaciones propias de la psicología tradicional, como la de los Siete Soplos de la tradición hindú (vid., en este sentido, id., «Sobre la psicología india y tradicional...», p. 334340, donde los Siete Soplos se vinculan con los Siete Rsis o Siete Sabios de los vedas, y estos con las siete estrellas de la Osa Mayor; vid., además supra n. 40 para la relación entre los Siete Soplos y los Marut).

47. «De Dios, Gorazón del universo, parten extensiones infinitas que se dirigen una hacia arriba y otra hacia abajo, esta a la derecha y aquella a la izquierda, una hacia delante y otra hacia atrás. Dirigiendo la mirada hacia estas seis extensiones, como hacia un mundo siempre igual, Dios consuma el mundo. Él es el principio y el fin, el $A$ y la $\Omega$; en él se consuman las seis fases del tiempo, y de él reciben su extensión indefinida: ese es el secreto del número Siete» (apud J. Hani, Mitos, ritos..., p. 330). 
apreciar significados de orden simbólico o (por utilizar la terminología tradicional) «suprahistórico», habrá que bucear en aquellos que con toda seguridad transmiten otros motivos de la trama, como (señaladamente) la decapitación de los héroes ${ }^{48}$, la figura de doña Lambra como posible trasunto de la «dama odiosa», la interpretación ornitomántica y la figura del ayo Nuño Salido, el héroe de origen extranjero y ascendencia cuestionada (que, a su manera, «reúne lo disperso»), el anillo como señal de reconocimiento, la visión recuperada de Gonzalo Gustioz, etc., con la esperanza de hallar en estas «maravillas» las mentiras más profundas de la leyenda.

48. Se trata este de un motivo sin duda crucial en la urdimbre simbólica del texto, al que no podrá soslayarse su componente sacrificial. Existe un trabajo de Colin SMITH, «The "Siete Infantes" Reborn in Scotland», La Corónica, 18 (2), Spring, 1990, p. 83-90, en que nuestra leyenda se pone en relación con otra escocesa (que remite a hechos del siglo XVII) con la que comparte algunas semejanzas, en particular la aparición de siete cabezas decapitadas en contexto de luchas de clan (Smith llega a sugerir la posible influencia directa del relato castellano, en virtud de supuestas estancias en España del mayor divulgador del texto escocés, el poeta Iain Lom). La leyenda en cuestión, en virtud de la relevancia que en ella cobra la vinculación de las cabezas con el agua (pues incluye el lavatorio de ellas y su asociación postrera a un «Well of the Seven Heads») presenta sumo interés para el estudio de «rituales» como el de las «Mojadas de Caballar» (nombre este del pequeño pueblo segoviano donde se ha conservado), pues en él confluyen el elemento acuático, el relato (en este caso hagiográfico) con decapitación y la veneración actual de los cráneos-reliquia (vid. Tomás Calleja Gujarro, Las Mojadas de Caballar: ‘milagro, superstición, o?, Segovia: Caja de Ahorros y Monte de Piedad, 1988). Nótese que las cabezas de los infantes de Lara también reposan en la iglesia de Salas, y que, según recuerda C. Smith, ibid., p. 88-89, Menéndez Pidal, en la descripción de su recorrido por los «lugares del Cantar viejo» se detiene en la cumbre del pinar de Canicosa para advertirnos que aquel era «el lugar donde, según los Cantares, vio Nuño Salido en los agüeros el desgraciado fin que esperaba a sus criados»; y añade: «Aun hoy [circa 1896] se conserva memoria del paso de los Infantes por este pinar, pues se cuenta que yendo por él, cansados de la sed, arrojó uno de los hermanos "la barra" a lo lejos y la clavó al pie de un pino, diciendo: "que cuando Dios quería agua allí había”. Allí brotó una fuente que hoy se llama de los Siete Infantes» (R. MEnÉndez PidAL, op. cit., p. 195). 